\title{
Managing Conflicts (Malay Version)
}

\section{Iqbal U*}

History Programme, Faculty of Social Sciences and Humanities, National University of Malaysia, Malaysia

*Corresponding author: Iqbal U, History Programme, Faculty of Social Sciences and Humanities, National University of Malaysia, UKM 43650, Bangi Selangor, Malaysia, Tel: 60389215555; E-mail: uqbah@siswa.ukm.edu.my

Received date: January 06, 2016; Accepted date: February 02, 2016; Published date: February 06, 2016

Copyright: (c) 2016 Iqbal U. This is an open-access article distributed under the terms of the Creative Commons Attribution License, which permits unrestricted use, distribution, and reproduction in any medium, provided the original author and source are credited.

Keywords: Interpersonal conflict; Human relations; Lacking awareness; Conflict of interest

\section{Commentary}

This book is written for readers' food for the soul related conflicts that occur every day in the world of modern and sophisticated. If there is no conflict with colleagues, superiors or people in the vicinity, we are still in conflict with ourselves. Although this book focuses on the conflict in the workplace, but how to manage conflict is suitable and can be used in everyday life for people in our environment. When we are in conflict with parents, what can we do? What about friends? This book provides guidance and memory to face such situations. This book provides guidance only, but the best way to manage conflicts is through the experience of the readers themselves. With this book, we can identify processes and measures to be taken in dealing with the conflict and the key is patience.

The phenomenon of conflicts in everyday life either on themselves or others should be emphasized. Conflict occurs in all stages of life, age, race, level of organization, status and so on. However, conflict resolution preferably can produce results that give satisfaction to the parties in conflict. In a nutshell, the conflict occurs when there is a conflict in terms of interests, values, objectives or anything different with our opinions. Sometimes we express those conflicts but also our common store of discontent when in conflict with the boss and who has good relations with superiors.

According to Deutsch, there are several factors that can influence the conflict in relationships between individuals. Interpersonal conflict occurs when two or more people interact. Conflicts between individuals that occur in human relations consist of two categories, namely constructive and destructive conflicts. There are four criteria in constructive conflict and six criteria in destructive conflict. Conflicts occur due to various causes in the relationship. Among them is the self, the environment or even the type of issues involved. Perhaps the size of the issue that sparked the conflict is great but with inner strength and good relations between the parties in conflict, a conflict may occur at minimum levels.

The effects of conflict are many. It depends with who we are in conflict. In general appearance of a conflict can be divided into several sections which affects the individual, inter-personal relationships, the impact on the issue and finally the impact on the resolution and the result of the conflict. Conflict does not only have negative consequences, even a positive effect also exists if it can be addressed in a thoughtful and insightful. There are several ways to manage conflict. If any of these methods are used in appropriate situations, it works effectively than any other means. One way to deal with conflict may not be suitable for all situations. A situation or conflict situations may require more than one way to manage conflict. One way to manage conflict can be combined with another way to get a better impression.

When there is a conflict, no matter with whom, there is any matter which is the reason they occur or cause conflict. Among the important skills before manage and resolve conflicts, the anger needs to be addressed. If we cannot control anger, all efforts before the confrontation with the others become meaningless. Its control is the same as the body control. Such as the hands and feet, we can control the anger in ways that are discussed in this book. Things that should be included in listening skills are things we already know but lacking awareness in using it. This is why we are stuck with the negative effects of conflict.

In addition to listening, words have to be spoken in a constructive way that is constructive and reassuring manner. When we tell the truth, it can become a weapon if there are parties attack us from behind. Honesty is important, but do require skills. When the two sides jointly won the conflict, both of them benefited in terms of accepted whole-heartedly. The method of solving the problem should be used for best results. There are several steps that can be taken and used in the settlement of this conflict. There are some guidelines in this book that can be followed to address the defensive, aggressive and passive parties. There are also people who love to make other people feel uncomfortable, such as calling a title which is not pleasant to hear, to criticize others in front of many people and many others.

When the other party became aggressive like patting the table, kicking chairs or verbally like screaming, ringing voice and the like, this book provides guidance to face the aggressive side. Sometimes also the conflicting parties do not interested to cooperate in resolving the conflict. From facial expressions, gestures and words, we know that them does not interest to discuss. Even if it were, the answer is short and unspecific. To sum up this book, the discussion revolves around the definition of conflict until the factors, conflict of interest and so on tips that can be used to address the conflict. Such information can open our eyes and minds to be more open in the face of conflict whether it is big or small conflict. 